\title{
Diagnosing skull fracture in children with closed head injury using point-of-care ultrasound vs. computed tomography scan
}

\author{
Afsaneh Dehbozorgi ${ }^{1} \cdot$ Razieh Sadat Mousavi-Roknabadi ${ }^{1}$ S Seyed Rouhollah Hosseini-Marvast ${ }^{1,2} \cdot$ Mehrdad Sharifi $^{1}$. \\ Robab Sadegh $^{1} \cdot$ Faramarz Farahmand $^{1} \cdot$ Fatemeh Damghani $^{1}$
}

Received: 9 July 2020 / Revised: 19 October 2020 / Accepted: 21 October 2020 / Published online: 28 October 2020

(C) Springer-Verlag GmbH Germany, part of Springer Nature 2020

\begin{abstract}
Diagnostic and therapeutic interventions in children for traumatic brain injury, which is known as the most important complication in trauma, require special attention. This study aimed to evaluate the accuracy of point-of-care ultrasound (POCUS) in diagnosing skull fracture in children with closed head injury in comparison with computed tomography (CT) scan. The current prospective cross-sectional study was conducted on children (0-14 years old), who were referred to the emergency department of a general teaching hospital in Shiraz, southern Iran (January-March 2018), with close head injury and were suspected of bone fracture. The participants were selected using a convenience sampling. The results of POCUS performed by emergency medicine (EM) residents were compared with the results of CT scan, which was reported by radiologists and considered a gold standard. Then, diagnostic tests were calculated. A total of 168 children were enrolled, with the mean \pm standard deviation age of $6.21 \pm$ 3.99. The most affected areas in the skull were the frontal (34.5\%) and occipital areas (33.3\%). POCUS had a sensitivity and specificity of $81.8 \%$ (95\%CI, 48.2-97.7\%) and $100 \%$ (95\%CI, 97.7-100\%), respectively. Positive and negative predictive values were $100 \%$ and $98.7 \%$, with an accuracy of $98.8 \%$ in comparison with CT scan in the diagnosis of skull fracture.

Conclusion: The results showed that POCUS with a portable ultrasonography machine, performed by the EM's physicians, have high diagnostic precision and can be considered a tool in the management of patients with closed head injury.
\end{abstract}

\section{What is Known:}

- Some studies have investigated the accuracy of ultrasound in diagnosing skull bone fractures in children with closed head injury, but before conducting this survey, no definite evidence recommended POCUS for skull fracture in children with closed head trauma in the ED.

What is New:

- POCUS with a portable ultrasonography machine, performed by the EM's physicians, has high diagnostic precision and can be considered a tool in the management of patients with closed head injury.

Keywords Closed head injury $\cdot$ Traumatic brain injuries $\cdot$ Skull fracture $\cdot$ Ultrasonography $\cdot$ Emergency department

Communicated by Daniele De Luca

Seyed Rouhollah Hosseini-Marvast

hoseinimr@sums.ac.ir

Afsaneh Dehbozorgi

dehbozorgia@sums.ac.ir

Razieh Sadat Mousavi-Roknabadi

mousavi_razieh@sums.ac.ir

Mehrdad Sharifi

m_sharifi@sums.ac.ir

Robab Sadegh

sadeghrobab@yahoo.com
Faramarz Farahmand frama1347@yahoo.com

Fatemeh Damghani dr.f.damghani@gmail.com

1 Emergency Medicine Department, Faculty of Medicine, Shiraz University of Medical Sciences, Shiraz, Iran

2 Emergency Medicine Department, Faculty of Medicine, Namazi Hospital, Shiraz University of Medical Sciences, Shiraz 7193711351, Iran 


$\begin{array}{ll}\text { Abbreviations } \\ \text { AUC } & \text { Area under the curve } \\ \text { CI } & \text { Confidence interval } \\ \text { CT } & \text { Computed tomography } \\ \text { ED } & \text { Emergency department } \\ \text { EM } & \text { Emergency medicine } \\ \text { MRI } & \text { Magnetic resonance imaging } \\ \text { NLR } & \text { Negative likelihood ratio } \\ \text { NPP } & \text { Negative predictive value } \\ \text { PLR } & \text { Positive likelihood ratio } \\ \text { POCUS } & \text { Point-of-care ultrasound } \\ \text { PPV } & \text { Positive predictive value } \\ \text { ROC } & \text { Receiver operating characteristic } \\ \text { SD } & \text { Standard deviation } \\ \text { TBI } & \text { Traumatic brain injury } \\ \text { US } & \text { Ultrasonography }\end{array}$

Introduction

Trauma is known as an important cause of mortality and disability, especially amongst children $[1,2]$. Head injury is a public health issue with about $30 \%$ of it leading to skull fractures $[3,4]$. It was estimated that annually, 2 million cases of head injury occurred in the USA [4]. It can cause many complications, such as skin damage, soft tissue injuries, bone fractures, and brain tissue injuries, which are known as traumatic brain injury. Traumatic brain injury (TBI), which is defined as a disruption in the normal brain's function, can involve both adults and children, but its pathophysiology and management are different in children [2].

When the skull is fractured, the dura mater is prone to damage. Dural laceration is common in diasthetic skull fractures and should be diagnosed because of its complications [5]. Head CT scan, an X-ray-based modality, is widely used to diagnose skull fracture and TBI. Children are more sensitive to ionizing radiation, and the relative risk of cancer is higher in them $[6,7]$. Given the dangers of using X-rays and computed tomography (CT) scan, physicians are attempting to reduce the use of these methods as much as possible. Solutions include the development of clinical guidelines to reduce unnecessary exposure or alternative imaging methods such as magnetic resonance imaging (MRI) or ultrasonography (US) [8].

US is a noninvasive tool that is superior to CT and MRI for detecting dura's status. Also, it is preferred over MRI due to it being more available in the emergency department (ED) [5]. Rabiner et al. stated the following benefits for point-of-care ultrasound (POCUS): (a) early diagnosis of a patient and early consultation; (b) reduction in $\mathrm{CT}$ scan request; (c) as a diagnostic tool when there is no access to CT scan; and (d) a triage tool in disaster area with difficult conditions [9]. Also, Weinberg et al. reported that the accuracy of POCUS was higher in diagnosing longitudinal bone fractures, especially in young adults and children with open growth plates, which can be used as a quick alternative to detect wrist fractures [10]. It is noticeable that POCUS may be a tool for detecting skull fracture; it does not rule out the brain lesion which might be more hazardous for the injured patients, and in the high-risk patients, CT scan should be performed [11-13].

Some studies have investigated the accuracy of ultrasound in diagnosing skull bone fractures, such as the study by Rabiner et al. [9], Trenchs et al. [14], Marin [15], and Riera and Chen [16]. All the mentioned studies highlighted the high sensitivity and specificity of POCUS for skull fracture clinical diagnosis. However, the aforementioned study sample sizes were low; hence, further studies were warranted to obtain sufficient evidence for pandemic usage. Therefore, the current study aimed to evaluate the accuracy of POCUS in diagnosing skull fracture in children with closed head injury in comparison with CT scan. The results would aid emergency physicians to speed up and reduce the cost of diagnosing TBI.

\section{Materials and methods}

\section{Study setting}

This prospective cross-sectional study (January-March 2018) was designed and conducted in the acute care II of the Emergency Medicine Department at Namazi Hospital, one of the biggest referral hospitals in southern Iran, with residency training program and more than 90,000 admission, annually. Moreover, about 1500-1800 children with trauma or surgery problems were admitted in this ED, too.

\section{Study population}

The study was performed on eligible patients who had referred to the ED. The inclusion criteria were children less than 14 years old with close head injury, suspected to skull fracture through physicians' physical examination, detectable place of injury through hematoma, or other specific findings, and according to existing algorithms, they required $\mathrm{CT}$ scan to rule out TBI [11]. Patients who required emergency actions such as airway management, and those parents who did not sign the written informed consent were excluded from the study.

\section{Sample size and sampling method}

Using the Arkin and Wachtel's method [17] as well as Medcalc software for Windows, a sample size of 100 patients was calculated to obtain a 95\% CI (standard deviation $(\mathrm{SD})=$ $5 \%$ ) with an estimation of $96 \%$ specificity for the diagnosis of skull fracture ( $\alpha=5 \%, \beta=20 \%$ ) [9]. But in order to increase the power of the study, 168 patients who met the inclusion 
criteria were enrolled. We used convenience sampling methods to collect the participants' data.

\section{Study protocol and interventions}

Skull skin ultrasonography was conducted using a portable ultrasonography machine (Mindray Z5, made in China) with linear probe in frequencies ranging $7-10 \mathrm{MHz}$, based on the method described by Marin et al. [18], by willing cooperative first year emergency medicine (EM) residents (4 physicians) supervised by ED attending physicians who were Iranian board-certified in EM, and faculty members who were expert in performing POCUS. POCUS is defined as one of the topics of EM curriculum and is taught to EM residents in Iran, during their program. In addition, the EM residents who participated in this study had attended a 1-day workshop on POCUS in diagnosis of skull fracture.

After using an US gel or using a water-separating pad, the transducer was placed on the impact site, often characterized by hematoma or other signs which show the site of injury. Using a high-frequency linear transducer, images were scanned at 2 horizontal levels throughout the length of the impact site. Due to the anatomical differences between the skull of children and adults, the operator must be familiar with young children's skull anatomy and aware of the differences in order to be able to correctly identify fractures. The twosided symmetric discontinuity usually shows the location of skull sutures. The discontinuation of bone under impact area that was not symmetric in comparison to the other side of skull reports as a skull bone fracture [18].

After recording the results, patients were referred to radiology department for head CT scan without using contrast. If any children need sedation, midazolam $0.1 \mathrm{mg} / \mathrm{kg}$ was administered. Since CT scan is considered the gold standard for diagnosing skull fracture, first/second year radiology residents, supervised by radiology-attending physicians, who were Iranian board-certified in radiology and faculty member, reported all the CT scan images. The radiologists were blinded to the results of the US, which were obtained in the ED. All data were recorded in the data gathering form.

\section{Statistical analysis}

All data were entered into the Statistical Package for Social Sciences version 19.0 (SPSS Inc., Chicago, IL, USA) and Medcalc for Windows for statistical analyses. The sensitivity, specificity, positive predictive value (PPV), negative predictive value (NPP), positive likelihood ratio (PLR), negative likelihood ratio (NLR), and the accuracy were calculated. In order to determine the best sensitivity and specificity and to obtain the area under the curve (AUC), receiver operating characteristic (ROC) curve was plotted. Kappa was used to assess the level of agreement between EM residents' POCUS results and the radiologists' report. Results are presented as mean \pm SD for continual variables and are summarized in number (percentage) for categorical ones. Two-sided $P$ value less than 0.05 and confidence interval (CI) of $95 \%$ were considered to be statistically significant.

\section{Results}

A total of 168 children were enrolled (Fig. 1), out of which $66.1 \%$ were male and the mean $\pm \mathrm{SD}$ of age was $6.4 \pm 3.9$ years. Eighteen (10.7\%) children needed sedation for CT scan to be performed. The age group $>4$ had the highest frequency $(61.3 \%)$. According to the patients' clinical features, the most affected areas of the skull were the frontal (34.5\%) and occipital areas (33.3\%) (Table 1). Using US, 9 (5.4\%) fractures were detected, whereas CT scan was able to identify 11 $(6.5 \%)$. In addition, 1 brain tissue injury was diagnosed using CT scan (Table 2). The level of agreement between EM residents' POCUS results and the radiologists' $\mathrm{CT}$ reports was 0.9 (95\%CI, 0.8-1.0).

POCUS had a sensitivity and specificity of $81.8 \%(95 \% \mathrm{CI}$, 48.2-97.7\%) and 100\% (95\%CI, 97.7-100\%), respectively, with an accuracy of 98.8 (95\% CI, 95.8-99.9) in comparison with CT scan which is considered the gold standard for diagnosing skull fracture. NLR was obtained at 0.2 (95\% CI, 0.1$0.6)$ (Table 3). Figure 2 shows the ROC curve of POCUS in diagnosing skull fracture in children with closed head injury, with the AUC obtained at 0.9 (95\%CI, $0.85-0.95, P<$ 0.0001). Examples of skull fracture in CT scan, as well as normal skull and fracture in skull ultrasound, are shown in Fig. 3.

\section{Discussion}

Although the use of this method is not common because pointof-care skull ultrasonography has not yet been included in clinical guidelines, we use this method in our ED to reduce the use of CT scans by observing legal considerations when visiting the patients. The algorithm provided by PECARN is widely used to decide in performing $\mathrm{CT}$ scans in children with head trauma [11]. In this algorithm, the use of CT for children with a moderate risk for brain injury has always been challenged, especially when the child visits by an ED physician in a center where there is no CT scan, and the physician wants to refer the child to a higher level center for CT. In this case, if the child is eligible for ultrasound, the location of the injury is clear, and the skin is not torn, ultrasound can be used to determine the existence of skull fracture which would be an indication to perform $\mathrm{CT}$ in order to discard intracranial injuries. 


\section{Enrollment}

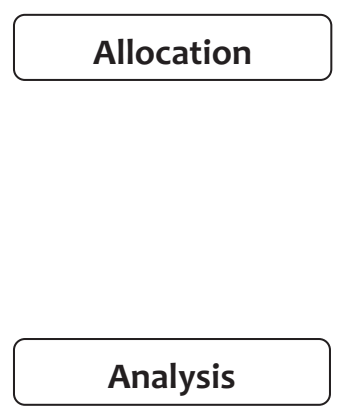

Allocated to intervention $(n=168)$

- Received allocated intervention $(n=168)$

- Did not receive allocated intervention (Not sign the written informed consent) $(n=4)$

Fig. 1 Flow diagram of enrolled patients

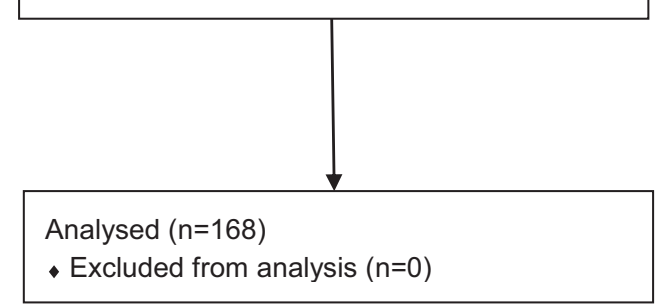

Table 1 Patients characteristics and clinical findings

\begin{tabular}{|c|c|c|c|c|}
\hline Characteristics & Total $(n=168)$ & $\begin{array}{l}\text { Skull bone fracture } \\
\text { in the CT scan }(n=11)\end{array}$ & $\begin{array}{l}\text { Without skull bone fracture } \\
\text { in the CT scan }(n=157)\end{array}$ & $P$ value \\
\hline \multicolumn{5}{|l|}{ Age group } \\
\hline Mean \pm SD & $6.4 \pm 3.9$ & $3.2 \pm 2.4$ & $6.5 \pm 3.9$ & $0.003 *$ \\
\hline $\begin{array}{l}\geq 4 \\
5-9\end{array}$ & $\begin{array}{l}65(38.7 \%) \\
53(31.5 \%)\end{array}$ & $\begin{array}{l}7(77.8 \%) \\
2(22.2 \%)\end{array}$ & $\begin{array}{l}58(37.7 \%) \\
51(33.1 \%)\end{array}$ & \multirow[t]{2}{*}{$0.043^{*}$} \\
\hline$\geq 10$ & $45(27.6 \%)$ & $0(0 \%)$ & $45(29.2 \%)$ & \\
\hline \multicolumn{5}{|l|}{ Gender } \\
\hline $\begin{array}{l}\text { Male } \\
\text { Female }\end{array}$ & $\begin{array}{l}111(66.1 \%) \\
57(33.9 \%)\end{array}$ & $\begin{array}{l}6(54.6 \%) \\
5(45.4 \%)\end{array}$ & $\begin{array}{l}105(66.9 \%) \\
52(33.1 \%)\end{array}$ & 0.53 \\
\hline \multicolumn{5}{|l|}{ Scalp hematoma } \\
\hline $\begin{array}{l}\text { Frontal } \\
\text { Occipital }\end{array}$ & $\begin{array}{l}58(34.5 \%) \\
56(33.3 \%)\end{array}$ & $\begin{array}{l}0(0 \%) \\
2(18.2 \%)\end{array}$ & $\begin{array}{l}58(36.9 \%) \\
54(34.4 \%)\end{array}$ & \multirow[t]{5}{*}{$0.002 *$} \\
\hline Left parietal & $18(10.7 \%)$ & $3(27.3 \%)$ & $15(9.6 \%)$ & \\
\hline Right parietal & $16(9.6 \%)$ & $2(18.2 \%)$ & $14(8.9 \%)$ & \\
\hline Right temporal & $12(7.1 \%)$ & $2(18.2 \%)$ & $10(6.4 \%)$ & \\
\hline Left temporal & $8(4.8 \%)$ & $2(18.2 \%)$ & $6(3.8 \%)$ & \\
\hline \multicolumn{5}{|l|}{ Ultrasound report } \\
\hline $\begin{array}{l}\text { Normal } \\
\text { Fractures }\end{array}$ & $\begin{array}{l}159(94.6 \%) \\
9(5.4 \%)\end{array}$ & $\begin{array}{l}2(18.2 \%) \\
9(81.8 \%)\end{array}$ & $\begin{array}{l}157(100 \%) \\
0(0 \%)\end{array}$ & $0<0.0001 *$ \\
\hline \multicolumn{5}{|c|}{ Brain tissue $\mathrm{CT}$ report } \\
\hline $\begin{array}{l}\text { Normal } \\
\text { Injured }\end{array}$ & $\begin{array}{l}167(99.4 \%) \\
1(0.6 \%)\end{array}$ & $\begin{array}{l}10(90.9 \%) \\
1(9.1 \%)\end{array}$ & $\begin{array}{l}157(100 \%) \\
0(0 \%)\end{array}$ & 0.065 \\
\hline
\end{tabular}

$C T$ computed tomography, $S D$ standard deviation

*Statistically significant 
Table 2 The results of point-of-care ultrasound in diagnosis of skull fracture in children with head trauma

\begin{tabular}{|c|c|c|c|}
\hline & \multicolumn{2}{|l|}{ CT scan } & \multirow[t]{2}{*}{ Total } \\
\hline & Positive & Negative & \\
\hline \multicolumn{4}{|c|}{ Point-of-care ultrasound } \\
\hline Positive & $9(81.8 \%)$ & $0(0 \%)$ & $9(5.4 \%)$ \\
\hline Negative & $2(18.2 \%)$ & $157(100 \%)$ & $159(94.6 \%)$ \\
\hline Total & 11 & 157 & 168 \\
\hline$P$ value & \multicolumn{3}{|l|}{$0<0.0001 *$} \\
\hline Level of agreement & \multicolumn{3}{|c|}{$0.894(95 \%$ CI, $0.748-1.0)$} \\
\hline
\end{tabular}

The results of our study showed that out of 168 patients who were enrolled in this study, POCUS had high sensitivity, specificity, and accuracy. Although a wide range of 95\% CI for sensitivity (48.2-97.7\%) may be a high chance of false negatives (due small sample size in patients with positive skull fracture in CT scan), high positive and negative predictive values in comparison with $\mathrm{CT}$ scan show that this tool can detect true-positive and true-negative cases, correctly; hence, POCUS can be considered a diagnostic tool in the screening of skull fractures in children with closed head injury when the risk of intracranial lesions is low. Also, obtained NLR less than 0.5 in our population $[0.2(95 \% \mathrm{CI}, 0.1-0.6)]$ means that lower probability of skull fracture to be present in suspicious children with a negative POCUS. But, due to low prevalence of skull fracture in our population with wide range of $95 \% \mathrm{CI}$, POCUS can be used in combination of other signs or findings in order to rule out more efficiently the existence of skull fracture in the patients with low risk. Our results were in line with Gordon et al.'s study that they found pooled PLR of 14.4 and NLR of 0.14 , although our patients with positive skull fracture in CT scan were low. Even though they showed in their meta-analysis that POCUS significantly increases the

Table 3 Diagnostic values of point-of-care ultrasound in diagnosis of skull fracture in children with closed head injury in comparison with CT scan

\begin{tabular}{ll}
\hline Diagnostic values & Values (95\%CI) \\
\hline Sensitivity & $81.8 \%(48.2-97.7 \%)$ \\
Specificity & $100 \%(97.7-100 \%)$ \\
Positive predictive value (PPV) & $100 \%(66.4-100 \%)$ \\
Negative predictive value (NPV) & $98.7 \%(95.5-99.8 \%)$ \\
Positive likelihood ratio (PLR) & - \\
Negative likelihood ratio (NLR) & $0.2(0.1-0.6)$ \\
Accuracy & $98.8 \%(95.8-99.9 \%)$ \\
Area under curve & $0.9(0.86-0.95)$ \\
$P$ value & $P<0.0001 *$ \\
\hline
\end{tabular}

CI confidence interval

*Statistically significant

\section{Ultrasound}

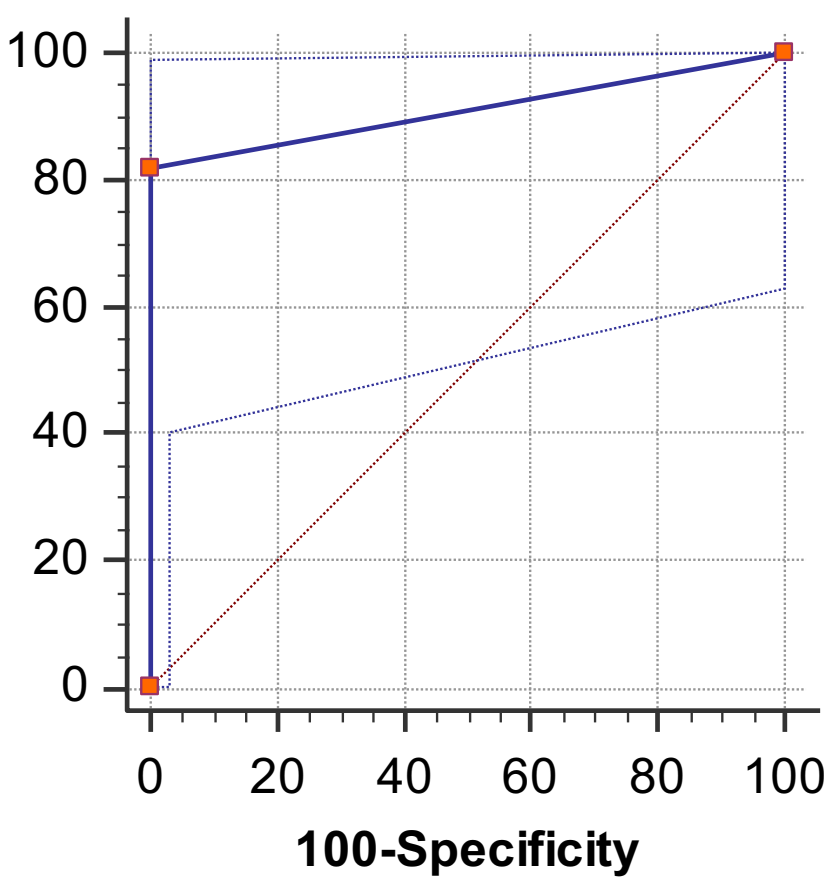

Fig. 2 ROC curve of point-of-care ultrasound in diagnosis of skull fracture in children with closed head injury in comparison with CT scan. Area under the curve is 0.9 (95\% CI, 0.85-0.94, P $<0.0001$ )

probability of skull fracture in children with closed head injury with pooled sensitivity of $91 \%$ and specificity of $96 \%$ [19], we performed this survey before their article's publication, and we thought that we should publish our findings. Finally, they stated that a positive POCUS can increase the probability of skull fracture, whereas a negative test decreases the probability.

The specificity of this modality in the current study was $100 \%$, while in the study by Parri et al. [20], which had the highest number of sample size before this study, it was reported to be $85.2 \%$. This significant difference might be due to the number of patients diagnosed with skull fracture in the mentioned study, and the number might be closer to reality. Rabiner et al. [9] reported that POCUS had a sensitivity of $88 \%$ and a specificity of $97 \%$, but our results showed more sensitivity and specificity. Weinberg et al. [10] obtained a sensitivity of $100 \%(95 \% \mathrm{CI}, 20-100)$ and a specificity of $100 \%$ (95\%CI, 79-100), but their sample size was only 10 patients. Choi et al. found that in 87 children $0-4$ years, POCUS had the sensitivity and specificity of $76.9 \%$ and $100 \%$ [21]. Masaeli et al. reported a sensitivity and specificity of $92.3 \%$ and $95.9 \%$, for POCUS in diagnosing skull fractures [22].

In Choi et al.'s study [21], 3 false negatives were observed, whereas in the current study, 2 false negatives were detected. One was a patient with a zygomatic arch fracture, which is not considered fracture of the skull bone, and the other had the 
Fig. 3 a Bone window in head CT scan, skull fracture in the occipital area mentioned by an arrow. b Normal skull in ultrasound. c Skull fracture in the ultrasound mentioned by an arrow. Disruption in the integrity of the outer layer of the skull in this image, in comparison to image $\mathbf{b}$, indicates a fracture
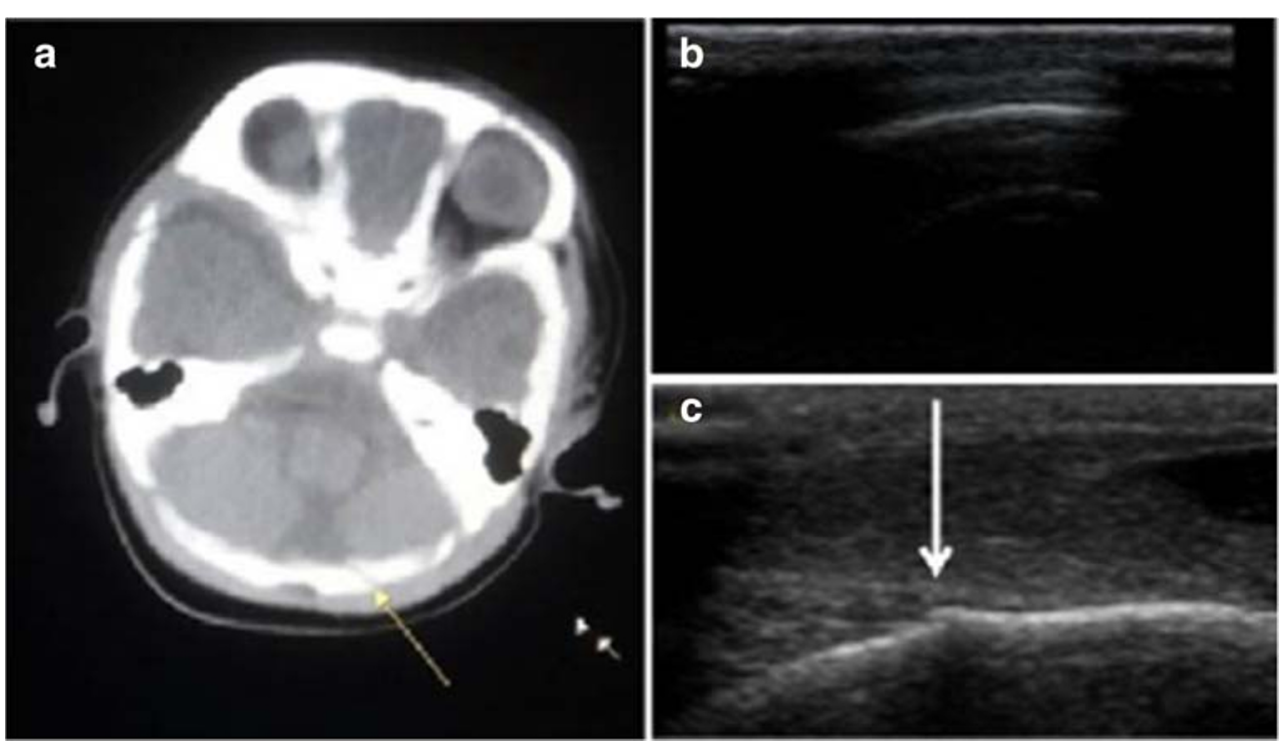

lambdoid suture region fracture, which was not diagnosed in POCUS. However, a study showed that US could be considered an effective tool for the diagnosis and evaluation of fracture in suture regions [5]. Hence, the reason of non-diagnosis could have been due to operator-based skill and accuracy in diagnosis.

On the other hand, the prevalence of skull fracture amongst 168 patients in this study was $6.6 \%$, while in other studies, this number varied between $11 \%$ in the study by Rabiner et al. [9] and $76.5 \%$ in Parri et al. [20]. It seems that stricter entry criteria in those studies might have led to enrolling patients with higher risk of skull fracture and traumatic brain injury, e.g., in Parri et al. study [20], which considered only hematoma as the point of fracture. Therefore, the mentioned studies obtained a higher rate of skull fractures. Also, children's parents asked to perform CT scan; hence, the number of normal CT scan was higher in this study.

Another difference was that in previous studies, emergency radiologist or EM specialist who conducted POCUS had been trained between an hour to a month [9, 11, 20]. In contrary, POCUS was conducted by the first year EM residents in our study. According to similarity in the design and results of this study with previous ones, it can be concluded that the skull US can be considered an easy modality that emergency physicians can use.

In the current study, a total of $58(34.5 \%)$ patients suffered from head trauma in the frontal area, but none of them had a positive POCUS or CT scan. It seems that more strict criteria should be considered for CT scan in patients with frontal trauma. In such patients, POCUS can have a significant role in reducing the number of exposure to ionizing radiation, especially in cases that parents are eager to do imaging. Also, in the previous studies, there were patients with TBI in the absence of skull fracture [20], but in the present study, only one patient had brain injury as well as skull fracture. Considering the significant relationship between skull fracture and TBI [23], POCUS should be used in combination with other clinical guidelines to reduce the frequency of exposure to X-rays. Moreover, patients with negative POCUS should be monitored within $2-4 \mathrm{~h}$ in the ED, and their parents should be trained about the warning signs at the time of discharge [24].

Consequently, POCUS is a modality that can be tolerated by patients and be used as a diagnostic tool for skull fractures in children, along with other existing algorithms such as PEACARN [11] to reduce CT scan usage, especially in patients with intermediated risk. If a skull fracture is diagnosed by POCUS, performing $\mathrm{CT}$ scan can rule out TBI. In the absence of skull fracture and other risk factors, patient could be observed and CT might not be indicated.

Although POCUS is considered a good diagnostic tool, extensive use of ultrasound to diagnose skull fractures has significant limitations. Firstly, the location of the injury has to be clearly identified; it is necessary that the skin does not have any damages. In many cases when they go to the ED, finding of the injury location is challenging. In the previous studies, the only factor in identifying the site of injury was the presence of hematoma, but in this study, we also identified other factors that determined the location of the injury, such as parental observation or scratching of the skin surface. Another point was the need for sedation in children to perform this procedure. Although none of the children in this study needed sedation for POCUS, the need for relaxation and immobility is always one of the challenges of performing ultrasound in children. Therefore, if possible, before trying to sedate with medication, it is recommended to first explain this method to the child and, with the help of parents, provide a suitable environment for the child to cooperate. In younger children, medications can be used if the child is not comfortable in the arms of the parents. So, the patient's cooperation and stillness are necessary to achieve reliable results. Another concern regarding 
POCUS is infection control. The probe should be cleaned before and after each usage with appropriate solutions, and if possible, a containing pad with special gel should be used to cover the probe to avoid direct contact with the patient's skin [25]. Being operator-based is another limitation.

It is worthy to say that the current study was conducted in a single center with convenience sampling method. Due to low prevalence of skull fracture in our studied population, specific studies evaluating the combination of POCUS with other signs in larger population might be useful to include POCUS in the diagnostic algorithms of patients with closed head injury.

\section{Conclusion}

According to the results, POCUS performed in the ED by emergency physicians has high diagnostic precision and can be considered a tool in the management of patients with closed head injury.

Acknowledgments The present article was extracted from the thesis written by Seyed Rouhollah Hosseini-Marvast in fulfillment of the requirements for certification as a specialist in EM, which was supported by Shiraz University of Medical Sciences (grant No. 94.01.01.10718). The authors wish to thank Mr. H. Argasi at the Research Consultation Center (RCC), as well as Parisa Chamanpara for statistical assistance at Center for Development of Clinical Research of Namazi Teaching Hospital.

Authors' contributions Afsaneh Dehbozorgi: study concept and design, searching the databases, data collection, writing manuscript, final approval

Razieh Sadat Mousavi-Roknabadi: searching the databases, data analysis, writing manuscript, final approval

Seyed Rouhollah Hosseini-Marvast: searching the databases, data collection, data analysis, writing manuscript, final approval

Mehrdad Sharifi: data collection, writing manuscript, final approval

Robab Sadegh: data collection, writing manuscript, final approval

Faramarz Farahmand: data collection, writing manuscript, final approval

Fatemeh Damghani: data collection, writing manuscript, final approval

Funding The current study was approved and financially supported by Shiraz University of Medical Sciences (grant No. 94.01.01. 10718).

Data availability Data will be presented if they are requested.

\section{Compliance with ethical standards}

Conflict of interest The authors declare that they have no conflict of interest.

Ethics approval This study was approved by the vice-chancellor of research and technology, as well as the local Ethics Committee (IR.sums.med.rec.1397.157) of Shiraz University of Medical Sciences. To consider an ethical issue, the collected data were kept confidential, except for the researchers.
Consent to participate Written informed consent was obtained from all individual participants' parents/guardian. Also, all participants' parents/ guardian signed the written informed consent.

\section{References}

1. Bishai D, Quresh A, James P, Ghaffar A (2006) National road casualties and economic development. Health Econ 15(1):65-81. https://doi.org/10.1002/hec. 1020

2. Araki T, Yokota H, Morita A (2017 Feb 15) Pediatric traumatic brain injury: characteristic features, diagnosis, and management. Neurol Med Chir (Tokyo) 57(2):82-93. https://doi.org/10.2176/ nmc.ra.2016-0191

3. Saadat S, Rashidi-Ranjbar N, Rasouli MR, Rahimi-Movaghar V (2011) Pattern of skull fracture in Iran: report of the Iran National Trauma Project. Ulus Travma Acil Cerrahi Derg 17(2):149-151. https://doi.org/10.5505/tjtes.2011.26043

4. Hofman PA, Nelemans P, Kemerink GJ, Wilmink JT (2000) Value of radiological diagnosis of skull fracture in the management of mild head injury: meta-analysis. J Neurol Neurosurg Psychiatry 68(4):416-422. https://doi.org/10.1136/jnnp.68.4.416

5. Muhammad G, Aurangzeb A, Khan SA, Hussain I, Alam S, Khan Afridi EA et al (2017) Dural tears in patients with depressed skull fractures. J Ayub Med Coll Abbottabad 29(2):311-315

6. Behnood HR, Haddadi M, Sirous S, Ainy E, Rezaei R (2017) Medical costs and economic burden caused by road traffic injuries in Iran. Trauma Mon 22(2). https://doi.org/10.5812/traumamon. 35997

7. Hall EJ (2002) Lessons we have learned from our children: cancer risks from diagnostic radiology. Pediatr Radiol 32(10):700-706. https://doi.org/10.1007/s00247-002-0774-8

8. Brenner DJ, Hall EJ (2007) Computed tomography-an increasing source of radiation exposure. N Engl J Med 357(22):2277-2284. https://doi.org/10.1056/NEJMra072149

9. Rabiner JE, Friedman LM, Khine H, Avner JR, Tsung JW (2013) Accuracy of point-of-care ultrasound for diagnosis of skull fractures in children. Pediatrics 131(6):e1757-e1764. https://doi.org/10. 1542/peds.2012-3921

10. Weinberg ER, Tunik MG, Tsung JW (2010 Aug) Accuracy of clinician-performed point-of-care ultrasound for the diagnosis of fractures in children and young adults. Injury 41(8):862-868. https://doi.org/10.1016/j.injury.2010.04.020

11. PECARN-California ACEP. https://californiaacep.site-ym.com/ page/PECARN?\&hhsearchterms $=\% 22$ pediatric + and + head + and + trauma\%22. Accessed November 21, 2018

12. Lee B, Newberg A (2005) Neuroimaging in traumatic brain imaging. NeuroRx. 2(2):372-383. https://doi.org/10.1602/neurorx.2.2. 372

13. McGrath A, Taylor RS Pediatric skull fractures. [Updated 2020 Aug 10]. In: StatPearls [Internet]. Treasure Island (FL): StatPearls Publishing; 2020. Available from: https://www.ncbi.nlm.nih.gov/ books/NBK482218/. Accessed 28 Oct 2020

14. Trenchs V, Curcoy AI, Castillo M, Badosa J, Luaces C, Pou J, Navarro R (2009) Minor head trauma and linear skull fracture in infants: cranial ultrasound or computed tomography? Eur J Emerg Med 16(3):150-152

15. Marin JR, Abo AM, Arroyo AC, Doniger SJ, Fischer JW, Rempell R, Gary B, Holmes JF, Kessler DO, Lam SHF, Levine MC, Levy JA, Murray A, Ng L, Noble VE, Ramirez-Schrempp D, Riley DC, Saul T, Shah V, Sivitz AB, Tay ET, Teng D, Chaudoin L, Tsung JW, Vieira RL, Vitberg YM, Lewiss RE (2016) Pediatric emergency medicine point-of-care ultrasound: summary of the evidence. Crit Ultrasound J 8(1):16. https://doi.org/10.1186/s13089-0160049-5 
16. Riera A, Chen L (2012) Ultrasound evaluation of skull fractures in children: a feasibility study. Pediatr Emerg Care 28(5):420-425. https://doi.org/10.1097/PEC.0b013e318252da3b

17. Arkin CF, Wachtel MS (1990) How many patients are necessary to assess test performance? JAMA 263(2):275-278

18. Marin J (2011) Novel applications in pediatric emergency ultrasound. Clin Pediatr Emerg Med 12(1):53-64. https://doi.org/10. 1016/j.cpem.2010.12.006

19. Gordon I, Sinert R, Chao J (2020) The utility of ultrasound in detecting skull fractures after pediatric blunt head trauma: systematic review and meta-analysis. Pediatr Emerg Care. https://doi.org/ 10.1097/PEC.0000000000001958 Publish Ahead of Print

20. Parri N, Crosby BJ, Mills L et al (2018) Point-of-care ultrasound for the diagnosis of skull fractures in children younger than two years of age. J Pediatr 196:230-236.e2. https://doi.org/10.1016/j.jpeds. 2017.12.057

21. Choi JY, Lim YS, Jang JH, Park WB, Hyun SY, Cho JS (2018) Accuracy of bedside ultrasound for the diagnosis of skull fractures in children aged 0 to 4 years. Pediatr Emerg Care. https://doi.org/10. 1097/PEC.0000000000001485 Publish Ahead of Print

22. Masaeli M, Chahardoli M, Azizi S, Shekarchi B, Sabzghabaei F, Fomani NS, Azarmnia M, Abedi M (2019) Point of care ultrasound in detection of brain hemorrhage and skull fracture following pediatric head trauma: a diagnostic accuracy study. Arch Acad Emerg Med 7(1):e53

23. Muñoz-Sánchez MA, Murillo-Cabezas F, Cayuela-Domínguez A, Rincón-Ferrari MD, Amaya-Villar R, León-Carrión J (2009) Skull fracture, with or without clinical signs, in $\mathrm{mTBI}$ is an independent risk marker for neurosurgically relevant intracranial lesion: a cohort study. Brain Inj 23(1):39-44. https://doi.org/10.1080/ 02699050802590346

24. Conforto I, Claudius A (2016) Head injury in infants and children. In: Tintinalli's Emergency Medicine: a comprehensive study guide, 8th edn. McGraw-Hill Education, pp 903-910

25. Shokoohi H, Armstrong P, Tansek R (2015) Emergency department ultrasound probe infection control: challenges and solutions. Open Access Emerg Med 7:1-9. https://doi.org/10.2147/OAEM. S50360

Publisher's note Springer Nature remains neutral with regard to jurisdictional claims in published maps and institutional affiliations. 